\title{
Taxes versus standards in a mixed economy
}

\author{
Bingxin Zeng ${ }^{1, *}$, Gaoqi Dai ${ }^{1}$ and Jin $\mathrm{Liu}^{1}$ \\ ${ }^{1}$ State Grid Energy Research Institute Co., Ltd, Beijing, China
}

\begin{abstract}
Governments have recently become increasingly concerned about environmental policy choice in a mixed economy because many countries are mixed economies where public and private firms engage in the output market. This paper provides an analytical framework to compare emission taxes and emission standards in a mixed economy. Through theoretical analysis and numerical example, two main conclusions are drawn. First, the ranking of emission taxes and standards in the aspect of bringing about greater social welfare depends on the policy stringency. More specifically, for high levels of environmental stringency, taxes yield a greater social welfare than the standards regulation does, while the opposite conclusion holds for low levels of environmental stringency. Second, the total production level under emission taxes is always larger than under emission standards. Our findings provide important implications for the policy choice and design in a mixed economy.
\end{abstract}

\section{Introduction}

Policymakers have become increasingly concerned with implementing an effective environmental policy to reduce greenhouse gas emissions because climate change poses a huge challenge to sustainability. Generally, market-based instruments, such as emission taxes, are preferred over command-and-control instruments, such as emission standards [1-4]. Most previous studies of policy comparison share one common assumption that the firm maximizes its own profits. However, many countries are mixed economies in which public (or partial privatization) and private firms engage in the output market [5]. The public firm maximizes social welfare while the private firm maximizes its own profits [6, 7]. Thus, some fundamental results in environmental economics may fail to hold in a mixed economy [5]. Therefore, it is worth studying environmental policy comparison in a mixed economy, which provides important implications for the environmental policy choice and design.

This paper compares the two popular environmental policies (i.e., emission taxes and emission standards) in a mixed economy. The main contributions of this article are as follows. First, many existing related studies ignore the fact that firms are not always looking for profit maximization in reality, especially for firms in developing countries. Motivated by providing policymakers with more insight and heightening its applicability, this paper studies this pressing issue. Second, this study contributes to the literature by investigating the environmental policy choice in a mixed economy. In fact, the choice of regulation instruments is the subject of much debated and studying from different aspects may yield completely opposite conclusions. There are a limited number of studies investigating environmental policy choice in a mixed economy $[8,9]$, but the result has been a matter of debate. Ref. [8] compared emission quotas with emission taxes in a mixed duopoly and pointed out that quotas are superior to taxes. Ref. [9] found that the parameters of the cost functions play a vital role in the superiority of emission quotas and emission taxes. In reality, taking into consideration policy implementation, an emission standard regulation is more common than an emission quotas regulation. Hence, the emission standard regulation is selected as the representative of command-and-control instruments in our study. Furthermore, to our knowledge, this paper is the first to address the effect of policy stringency on environmental policy choice in a mixed economy.

Through theoretical analysis and numerical example, two main conclusions are drawn. First, the ranking of emission taxes and standards in the aspect of bringing about greater social welfare depends on the policy stringency. More specifically, for high levels of environmental stringency, taxes yield a greater social welfare than the standards regulation does, while the opposite conclusion holds for low levels of environmental stringency. Second, the total production level under emission taxes is always larger than under emission standards.

The rest of the paper is organized as follows. Section 2 provides a literature review of the research on the mixed duopoly. Section 3 describes the model and some optimality analyses. Section 4 presents the policy comparisons. Conclusions and policy implications are summarized in the final section.

\section{$\overline{{ }^{*} \text { Corresponding author: muring@ } 163 . c o m}$}




\section{Literature review}

Following the seminal article [6], there is a large body of literature analyzing the issues of mixed duopoly. For example, Matsumura investigated the optimal level of privatization and found that neither full privatization nor full nationalization is optimal [7]. Ishibashi and Matsumura investigated R\&D competition in a mixed market by using a standard model of patent races [10]. Lee and Tomaru showed that the level of privatization does not influence the optimal output subsidy but does influence the optimal R\&D tax [11].

The application of the mixed duopoly model in the environmental field has not been extensively studied in the literature. On the one hand, the environmental performance of public firms and private firms was compared by theoretical research or empirical evidence [12-14]. On the other hand, some scholars studied the effect of the level of privatization on environmental damage [15-18].

Additionally, price competition versus quantity competition in a mixed economy has also attracted much attention. Price competition led to more profits for private firms [19], regardless of the decision-making sequence of firms and the nationality attributes of private firms [20]. But quantity competition led to more profits for private companies if the level of privatization was considered [21]. Moreover, price competition led to more social welfare when firms engage in the Cournot game [22].

From the above review, the issue of environmental policy comparison in a mixed economy has been little investigated. Furthermore, almost all scholars neglect the effect of policy stringency on policy choice in a mixed economy. Therefore, to heighten its applicability and provide policymakers with more insights into this issue, this paper aims to compares the two popular environmental policies (i.e., emission taxes and emission standards) in a mixed economy.

\section{The model}

Considering an industry with a representative public firm (firm 0 ), and a representative private firm (firm 1), each firm produces a homogeneous good. Without loss of generality, each unit of output generates a unit of emission.

The linear inverse demand function is given by $p=A-Q=A-q_{0}-q_{1}$, where $q_{0}$ and $q_{1}$ denote the output level of firm 0 and firm 1, respectively. The production cost function is assumed to be linear form, $c\left(q_{i}\right)=c q_{i}, c>0$. As usual, the abatement cost function $a c\left(a_{i}\right)=a_{i}^{2} / 2$, where $a_{i}$ is the emission reductions. Hence, the final emission after abatement is expressed as $e_{i}=q_{i}-a_{i}$.

As mentioned, the objective function of firm 0 is social welfare function $W$, while the objective function of firm 1 is profits function $\pi_{1}$.

The decision-making sequence of the regulator and firms is as follows. In stage 1, the regulator commits to a regulatory policy by announcing an emission tax or an emission standard. In stage 2, according to its own objective function, each firm choose its output and abatement level. The two stages mechanism is introduced by backward.

\subsection{Emission taxes}

Under emission taxes regulation, the regulator set a uniform tax $\tau$ to control the emission level of firms. In this case, firm $i$ 's profit is given by

$$
\pi_{i}=(p-c) q_{i}-\tau\left(q_{i}-a_{i}\right)-a_{i}^{2} / 2 .
$$

The social welfare $W_{T}$ is expressed as

$$
W_{T}=Q^{2} / 2+\pi_{0}+\pi_{1}+\tau\left(q_{0}-a_{0}+q_{1}-a_{1}\right)-D(E),(2)
$$

where $D(E)=d\left(e_{1}+e_{2}\right), d>0$ denotes the aggregate environmental damage.

According to the first order conditions (FOCs), we have:

$$
\begin{array}{lc}
q_{0}=A-c-2 d+\tau, & q_{1}=d-\tau, \\
a_{0}=d, & a_{1}=\tau .
\end{array}
$$

Thus, the total output and emissions level:

$$
\begin{gathered}
Q_{T}=A-c-d, \\
E_{T}=A-c-2 d-\tau .
\end{gathered}
$$

Therefore, the social welfare $W_{T}$ is given by

$$
W_{T}=\frac{A^{2}+c^{2}+2 d^{2}-\tau^{2}}{2}-d(A-c-\tau)-A c .
$$

\subsection{Emission standards}

Under emission standards regulation, the regulator set the uniform emission standard $\bar{e}$ to control the emission level of firms. In this case, firm $i$ 's profit is given by

$$
\begin{aligned}
& \pi_{i}=(p-c) q_{i}-a_{i}^{2} / 2 \\
& \text { s.t. } q_{i}-a_{i} \leq \bar{e}
\end{aligned}
$$

The social welfare $W_{S}$ is expressed as

$$
W_{S}=Q^{2} / 2+\pi_{0}+\pi_{1}-D(E),
$$

where $D(E)=d\left(e_{1}+e_{2}\right), d>0$ denotes the aggregate environmental damage.

Here, we suppose that the emission standard is binding, i.e., the optimal level of emissions is equal to $\bar{e}$. Then, the FOCs are given by:

$$
\begin{array}{lrl}
q_{0}=2(A-c-\bar{e}) / 5, & q_{1}=(A-c+\bar{e}) / 5, \\
a_{0}=(2 A-2 c-7 \bar{e}) / 5, & a_{1}=(A-c-4 \bar{e}) / 5 .
\end{array}
$$

Thus, the total output and emissions level:

$$
\begin{gathered}
Q_{S}=(3 A-3 c-\bar{e}) / 5, \\
E_{S}=2 \bar{e} .
\end{gathered}
$$

Therefore, the social welfare $W_{S}$ is given by

$$
W_{S}=\frac{8(A-c-\bar{e})^{2}-41 \bar{e}^{2}}{25}-2 d \bar{e} .
$$

\section{Policy comparisons}

To compare the two different environmental policies, we suppose that the purpose of the regulator is to have an 
equivalent effect on the reduction of aggregate emissions under different policies. And the greater stringency of environmental policies is measured by higher taxes or smaller standards. In this case, the greater social welfare under the same total emission level, the policy instrument performs better. Hence, we have the following equation:

$$
A-c-2 d-\tau=E_{T}=E_{S}=2 \bar{e} \text {. }
$$

That is, the emission standard $\bar{e}=(A-c-2 d-\tau) / 2$.

Therefore, the difference between the social welfare under the two different environmental policies can be expressed as

$$
\Delta W=W_{T}-W_{S} .
$$

By substituting Equations (5), (10) and (11) for Equation (12), we have

$$
\Delta W=\frac{-33 \tau^{2}-2(A-c-34 d) \tau+K}{100},
$$

where $K=3(A-c)^{2}-32 d^{2}-4(A-c) d$.

It is clear that the sign of $\Delta W$ depends on the emission tax $\tau$. In other words, the ranking of emission taxes and standards depends on policy stringency in a mixed economy.

To guarantee that all equilibrium results under two different environmental policies are nonnegative, we assume that the emission tax such that $\tau \in(0, d / 2)$.

Note that $\tau^{*}=\arg \max \Delta W(\tau)>0$ and $\Delta W\left(\tau^{*}\right)>0$. Thus it is easy to show that $\Delta W(\tau)$ is strictly increasing in the interval $(0, d / 2)$. Moreover, $\lim _{\tau \rightarrow 0} \Delta W(\tau)<0$ and $\lim _{\tau \rightarrow d / 2} \Delta W(\tau)>0$. Hence, $\Delta W(\tau)$ has one and only one root in the interval $(0, d / 2)$.

Hence, the difference between the social welfare is less than zero for low levels of environmental stringency, while the opposite conclusion holds for high levels of environmental stringency.

Therefore, standards yield a greater social welfare than the tax regulation does for low levels of environmental stringency, while the opposite conclusion holds for high levels of environmental stringency.

To illustrate the theoretical analysis result, a numerical example is presented, as shown in Figure 1.

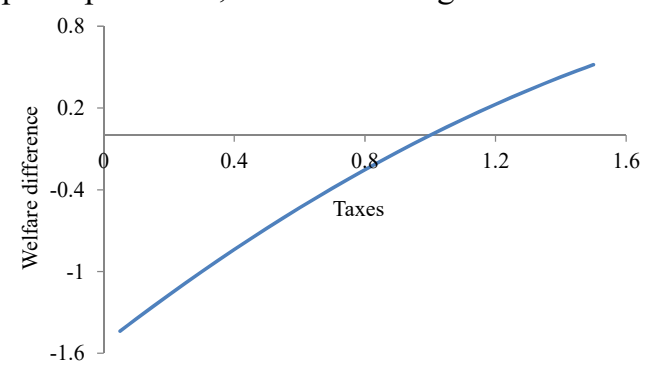

Fig1. Policy stringency and welfare difference

$$
\text { ( } A=10, c=1, d=3 \text { ) }
$$

Moreover, we compare the total production levels of firms under emission taxes and standards regulation in a mixed economy. The difference between the total production levels under the two different environmental policies can be expressed as

$$
\Delta Q=Q_{T}-Q_{S}
$$

By substituting Equations (3), (8) and (11) for Equation (14), we have

$$
\Delta Q=0.5 A-0.5 c-1.2 d-0.1 \tau \text {. }
$$

It is easy to see that $\Delta Q(\tau)>0$ in the interval $(0, d / 2)$. That is, the total production level under emission taxes is always larger than under emission standards.

\section{Conclusions}

Governments have recently become increasingly concerned about environmental policy choice in a mixed economy because many countries are mixed economies where public and private firms engage in the output market. This paper provides an analytical framework to compare emission taxes and emission standards in a mixed economy. Through theoretical analysis and numerical example, two main conclusions are drawn. First, the ranking of emission taxes and standards in the aspect of bringing about greater social welfare depends on the policy stringency. More specifically, for high levels of environmental stringency, taxes yield a greater social welfare than the standards regulation does, while the opposite conclusion holds for low levels of environmental stringency. Second, the total production level under emission taxes is always larger than under emission standards.

Our results provide policymakers with more understandings about the choice of environmental policy instruments in a mixed economy. An emission standard regulation is preferred when the government sets a lower emission reduction target in the initial. But an emission tax regulation is preferred when the deep emission reduction target is implemented. In conclusion, with the increase in emission reduction target set by the government, the policy for greenhouse gas emissions control switches from standards to taxes in a mixed economy.

For mathematical tractability, there are several limitations in our study. First, the assumption of a constant marginal environmental damage might be rigorous. More realistically, it would be even more general if environmental damage had a generic shape. Second, the proposed analytical framework can also be extended to the industry with a public firm and multiple private firms. These points are the main suggestions for the directions of future research.

\section{Acknowledgments}

The authors gratefully acknowledge financial support from the science and the technology project of State Grid Corporation of China (SGSC0000KXJS2000095). All remaining errors are the sole responsibility of the authors.

\section{References}

1. S.R. Milliman, R. Prince, J. Environ. Econ. Manag. 17, 247-265 (1989) 
2. C. Jung, K. Krutilla, R. Boyd, J. Environ. Econ. Manag. 30, 95-111 (1996)

3. J.P. Montero, J. Environ. Econ. Manag. 44, 23-44 (2002)

4. T. Requate, W. Unold, Eur. Econ. Rev. 47, 125-146 (2003)

5. G. Ye, J. Zhao, Environ. Resour. Econ. 65, 273-295 (2016)

6. G. DeFraja, F. Delbono, Oxford Econ. Pap. 41, 302311 (1989)

7. T. Matsumura, J. Public Econ. 70, 473-483 (1998)

8. T. Naito, H. Ogawa, Environ. Econ. Policy Stud. 10, 87-100 (2009)

9. K. Kato, Environ. Econ. Policy Stud. 13, 43-63 (2011)

10. I. Ishibashi, T. Matsumura, Eur. Econ. Rev. 50, $1347-$ 1366 (2006)

11. S.H. Lee, Y. Tomaru. Oper. Res. Lett. 45, 238-241 (2017)

12. D. Talukdar, C.M. Meisner, World Dev. 29, 827-840 (2001)

13. H. Wang, Y. Jin, Environ. Resour. Econ. 36, 255-273 (2007)

14. L.F.S. Wang, J. Wang, Econ. Sys. 33, 389-396 (2009)

15. H. Beladi, C.C. Chao, Econ. Lett. 93, 343-347 (2006)

16. B. Saha, Econ. Lett. 115, 97-99 (2012)

17. K. Kato, J. Econ. 110, 165-180 (2013)

18. R. Pal, B. Saha, Resour. Energy Econ. 40, 19-35 (2015)

19. A. Ghosh, M. Mitra, Econ. Lett. 109, $72-74$ (2010)

20. J. Haraguchi, T. Matsumura, Res. Econ. 68, 338353 (2014)

21. M. Scrimitore, J. Inst. Tho. Econ. 170, 684-703 (2014)

22. J. Haraguchi, T. Matsumura, J. Econ. 117, 117-136 (2016) 